\title{
SYNEIDESIS, PARA ALÉM DA FRAGMENTAÇÃO DO ESPÍRITO: UMA INTRODUÇÃO À TEORIA DO ABRANGENTE E DO PENSAR EM IMAGENS
}

\author{
Manuel Moreira da Silva
}

\begin{abstract}
Resumo: Este artigo discute a emergência da syneidesis (como consciência ativa concreta) e do pensar em imagens, na atualidade, em contraposição às discussōes contemporâneas em torno da consciência e do pensamento como representaçôes abstratas. A hipótese de trabalho assumida é de que a syneidesis - como consciência sociocultural ou ético-política, à qual os medievais designaram conscientia consequens (consciência retrospectiva ou consequente) - é histórica e ontologicamente anterior à consciência teórica individual, em suas múltiplas formas, e à consciência prática individual, daquela derivada. Essas duas são formas da que também se nomearia conscientia antecedens (consciência antecedente), típicas do pensamento da representação. Nessa perspectiva, de início, o artigo apresenta as linhas gerais da syneidesis e, ato contínuo, o pensar em imagens como seu elemento próprio.
\end{abstract}

Paravras-Chave: Syneidesis. Consciência concreta. Pensar em imagens. Representação.

\section{Posiçáo do PROBLEMA}

Este artigo discute o problema da consciência na época da fragmentação do espírito, isto é, na época atual, porquanto esta consiste na dissolução da razão enquanto conceito formal unificador das experiências humanas. Para isso, de início, expóe os traços mais gerais da consciência ativa concreta (real-

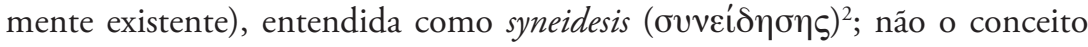

\footnotetext{
${ }^{1}$ Professor Adjunto do Departamento de Filosofia da Universidade Estadual do Centro-Oeste do Paraná, (Unicentro), Guarapuava, PR - Brasil. E-mail: immanuelmoreyra@gmail.com

Doutor em História da Filosofia Moderna e Contemporânea pela Universidade Estadual de Campinas (Unicamp). Psicanalista, docente e analista didata, vinculado à Sociedade Psicanalítica do Paraná, SPP/ PR. Publicou Interpretaçôes da Fenomenologia do espírito de Hegel (em coorganização com Leonardo Alves Vieira), Loyola, 2014, e Ser e pensar, inícios, Todas as Musas, 2016. Também é autor de artigos e capítulos de livros em revistas e obras coletivas no Brasil e no exterior.
}

${ }^{2}$ Neste trabalho, daremos preferência à forma transliterada do termo ora assinalado para nos referir à forma de consciência por ele indicada. Com esse procedimento, esperamos deixar o mais claro possível

http://dx.doi.org/10.1590/0101-3173.2018.v41esp.03.p13

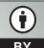

This is an open-access article distributed under the terms of the Creative Commons Attribution License. 
abstrato desta, mas, ao contrário, essa forma de consciência em si e para si mesma, a um tempo cognitiva ou intelectual e afetiva ou emocional, como consciência sociocultural ou ético-política - determinada formalmente pelos medievais como consciência retrospectiva ou consequente (conscientia consequens) (SCHINKEL, 2006, p. 181-182) - e, por isso, como forma ativa e concreta de um pensar igualmente ativo e concreto, então designado pensar em imagens ('̇े

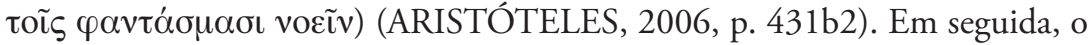
artigo apresenta este último como o meio adequado a partir do qual aquela consciência emerge.

À consciência concreta (realmente existente) designa-se aqui syneidesis, porquanto, do termo grego que a denomina, o latino conscientia se mostra, em sua origem, a derivação ou a transliteração primeira. Por isso, literalmente, tanto syneidesis quanto conscientia dizem originariamente "saber com" ("syn eidenai", termo neutro do qual advém, com o mesmo sentido, "syn oida" e "syn eidos"), expressão que deve ser interpretada, em rigor, como um "saber - em comum - com os outros" (OJAKANGAS, 2010; SCHINKEL, 2006) devido ao caráter a um tempo cognitivo ou intelectual e afetivo ou emocional, bem como sociocultural, do próprio termo que ele informa: "eidos". Este não se refere meramente à ideia ou à forma, tal como aparecem, de modo respectivo, em Platão e Aristóteles, mas também, ainda antes destes, concerne à maneira como o eidos mesmo emerge na Grécia antiga enquanto expressão distintiva do caráter intelectual ou cognitivo daquela cultura, tal como de outros povos que dela herdaram esse seu caráter. Essa, inclusive, abstraída de seus elementos vinculantes, a pressuposição básica da definição de "eidos" fornecida por The Oxford English Dictionaries. ${ }^{3}$

Desse modo, o sentido concreto e, assim, primeiro de synoida, syneidos e de syneidesis, ou ainda o de conscientia, não é senão o de uma consciência que se faz e se perfaz coletiva, social ou intersubjetivamente; portanto, com outra consciência. Nesse caso, a consciência em questáo constitui-se como a forma (eidos) unitária ou comum (syn) mediante a qual um povo, uma cultura

de que consciência o presente artigo trata e em que medida ele a distingue das formas de consciência usualmente em questão, nas mais diversas disciplinas científicas e filosóficas, desde a emergência da assim chamada consciência moderna. Em vista disso, bem como em decorrência do espaço exíguo de um artigo, o trabalho se limita a apresentar a coisa mesma - a consciência concreta como syneidesis - e seu correlato, o pensar em imagens.

${ }^{3}$ No original inglês: "The distinctive expression of the cognitive or intellectual character of a culture or social group". Disponível em: https://en.oxforddictionaries.com/definition/eidos. Acesso em: 14 nov. 2018. 
ou uma civilização, ou apenas um grupo social determinado, voltam-se para si mesmos ou se con-formam como tais; quando, a um tempo, a consciência em questão se faz igualmente teórica e prática, individual e social etc. ${ }^{4}$ Conforme Marietta Junior, embora a preocupação helenística pela ética e as atitudes internas do indivíduo fomentassem o desenvolvimento do conceito de consciência ética, o termo syneidesis e seus cognatos foram usados indistintamente em referência a questóes éticas e não éticas; por isso, os gregos não distinguiam consciência ética (conscience) e consciência teórica (consciousness), como fazem os falantes do inglês e outras línguas atuais (MARIETA JR, 1970, p. 178). Ainda segundo Marietta Junior, os aspectos éticos e não éticos (que se distinguem, em inglês, pelo termo "conscience") foram transmitidos pela mesma palavra, e apenas o contexto indicou a qualidade moral do objeto da consciência (MARIETA JR, 1970, p. 178). Para Marietta Junior, ao que parece, o sentido unitário, antes originário, do termo syneidesis ainda era o mesmo nos estoicos e no apóstolo Paulo, cujo uso do termo, conforme Ben Woodring (2012) e J. Dupont (1918) - este, no início do século passado -, corresponderia ao daqueles filósofos (DUPONT, 1918; WOODRING, 2012). Isso também ocorre com Freud, que, para Nauss (1962), retoma em sua noção de Além-eu (Übermensch) precisamente o sentido de syneidesis tal como este ocorre na Bíblia cristã (NAUSS, 1962).

Em todo caso, é precisamente com os estoicos que se inicia a separação de cognição e emoção ${ }^{5}$, tal como é com os medievais que, primeiramente, distinguem-se conscientia e syneidesis (synderesis) (SCHINKEL, p. 180ss). ${ }^{6}$ Isso permitiu a Boaventura, conforme Schinkel, atribuir uma função distinta à parte intelectiva e outra à parte afetiva da alma; caso em que à primeira coube o elemento intelectual e cognitivo e, à segunda, o elemento afetivo e, portanto, emocional, ético ou moral; o que levou à determinação e designação da primeira como consciência antecedente (conscientia antecedens), a consciência orientadora que opera antes do ato, e a consciência que opera posteriormente ao ato, a consciência retrospectiva ou consequente (conscientia consequens)

\footnotetext{
${ }^{4}$ Para outras interpretaçōes dos termos syneidesis, syneidos e seus derivados, ver, entre outros, (SCHINKEL, 2006; VIRASORO, 1963; MARIETTA JUNIOR, 1970).

${ }^{5}$ Sobre esse ponto e sua relevância para o presente, ver Schmitt (2008).

${ }^{6}$ Os medievais usam preferencialmente "syndéresis" em lugar de "syneidesis". Não obstante, "syndéresis" entrou para o vocabulário filosófico medieval como resultante de um equívoco na grafia de "syneidesis", por săo Jerônimo (ou de seu comentário por Pedro Lombardo) e, assim, tomou um caminho bastante diverso, ainda que tenha mantido alguns aspectos essenciais da syneidesis. Ver, a respeito, (WALDMANN, 1938; ALBERTUNI, 2010).
} 
(SCHINKEL, 2006, p. 181-182). Tal distinção, pode-se dizer, assentou mais um dos tijolos que ajudaram a construir a assim chamada época moderna, do ponto de vista do pensamento e da consciência em geral, estabelecendo uma clara distinção entre os tempos modernos e a época que os precedera. Essa situação hoje parece inverter-se, pois, com a consumação e a respectiva dissolução da modernidade como época presente, a consciência própria dessa época também se fragmenta e se dissolve, deixando, portanto, a descoberto aquele núcleo a partir do qual ela se construíra, sobre o qual apôs suas determinaçóes formais e categorias transcendentais. Assim, a chamada teoria da consciência termina por se perder em um labirinto tal que - como o de Fauno, o filme ${ }^{7}$ -, em rigor, não prenuncia senão o retorno do próprio Fauno, Pan $(\pi \alpha v)$; em nosso caso, da syneidesis em sua integridade, anterior à cisão, e ao mundo que nela e através dela se manifesta.

Este artigo afirma, pois, a tese de que, anterior à distinção de cognição e emoção ou de intelecção e afecção, a syneidesis se constitui como expressão

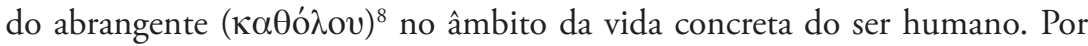
sua vez, o abrangente ( qual ser e conceber são um e o mesmo, sendo aquele, a um tempo, o ser-um e o ser-outro destes: nele, não há distinção entre sensível e inteligível ou entre sensação e inteligência; donde ele também não ser nem o Uno transcendente (ao mundo) dos neoplatônicos, nem o absoluto imanente (à natureza e ao espírito) de Hegel, mas o princípio manente, ou estruturante, não-causal, de

\footnotetext{
${ }^{7}$ Ver O labirinto do fauno, direção de Guillermo del Toro, Espanha, 1944, Com Ivana Baquero, Sergi López, Doug Jones, Ariadna Gil, Maribel Verdú. O filme retrata a promessa da imortalidade e a impossibilidade de sua doação aos humanos, no contexto de uma Espanha franquista, em 1944, com a Guerra Civil oficialmente terminada, mas com rebeldes ainda em combate na região de Navarra. A esse campo de batalha chegam Ofélia (Ivana Baquero), 10 anos, e sua mãe Carmen (Ariadna Gil), para viverem com o novo padrasto da menina, Capitấo Vidal, um oficial fascista empenhado em exterminar quem a ele se interpóe. Em contraponto ao Capitáo incapaz de pensar, aberta à imaginaçáo e à fantasia, Ofélia se descobre, com Fauno e em seu labirinto, princesa imortal do reino subterrâneo, do qual havia fugido para conhecer o mundo humano; a fim de reassumir sua condição eterna, ela deve passar por três provas, de modo que, assim, a árvore da vida renasça e a memória do mundo de outrora se restabeleça. De volta a este, sinais de sua passagem pelo mundo humano se tornam visíveis a quem saiba para onde olhar.

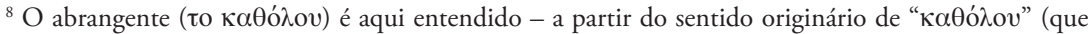
assim traduzimos por "abrangente"), em Aristóteles, bem como de sua interpretação fornecida por Philip Merlan - como um elemento concreto e, dessa maneira, comum a tudo que é o caso, a todas as

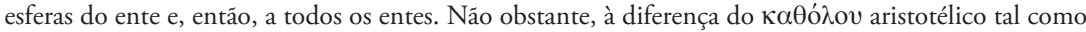
interpretado por Merlan, o $\kappa \alpha \theta$ ó $\lambda o v$ aqui assumido e mantido não é tomado como uma esfera suprassensível, acima e, portanto, oposta à sensível, mas antes se impóe como anterior à distinçáo mesma de

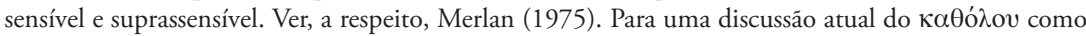
abrangente, veja-se Da Silva (2016).
} 
tudo o que há. Quer dizer, o princípio que permanece dentro de si mesmo, na medida em que - como início, arché, de tudo o que há - se expande no que há e como o que há, bem como, enquanto ocaso de tudo o que há, contrai-se dentro de si a si mesmo, fazendo com que o que há retorne igualmente dentro de si a si mesmo, isto é, ao seu início, ao próprio abrangente, que jamais sai de si. Ser e conceber são modos do abrangente, que é o ser-um deles, bem como aqueles, enquanto se mostram, em sua alteridade, o ser-outro deste.

No ser-outro do abrangente ou, o que é o mesmo, na alteridade de ser e conceber, emerge tudo o que há. De início, o real (ou o singular) e o ideal (o universal): este, enquanto elemento vinculante daquele a si mesmo como tal; aquele, enquanto acontecimento singular e inapreensível, logo não-vinculável. Em seguida, o seer (Seyn) (o acontecer que se apropria de seu próprio ser) e a ideia ( $\llcorner\delta \varepsilon \alpha)$ (o ser apropriado de um acontecer determinado formalmente), ambos - ideia e seer - os respectivos inícios formais determináveis como inicio do pensar até aqui, ambos, contudo, igualmente incapazes de proceder ao inicio mesmo, porquanto sua razão de ser não é senão a cisão ou a alteridade de ser e conceber ou, antes, a cisão ou a alteração do próprio abrangente. Este, aquele início mesmo que não é início apenas do pensar, mas também do seer e da ideia, e cujo pensar não é senão o pensar de si mesmo, isto é, do abrangente: o pensar a um tempo puro, porque do próprio abrangente enquanto ser-um de ser e conceber, e, em imagens, porque no abrangente, porquanto este se perfaz no haver, enquanto ser-outro de ser e conceber ou, em suma, do abrangente ele mesmo. Enfim, embora a syneidesis exprima em si o ser-um de ser e conceber, porque ela se dá ou acontece na alteridade, seu pensar próprio - e com isso ela mesma - se constitui como tal no elemento do pensar em imagens.

A seguir, em vista do exposto acima, este artigo discute a emergência da syneidesis e do pensar em imagens, na atualidade, em contraposição às discussóes contemporâneas em torno da consciência e do pensamento como representação abstrata. Assim, a hipótese de trabalho assumida é a de que a syneidesis, como consciência ativa concreta (realmente existente), é histórica e ontologicamente anterior à consciência teórica individual, em suas múltiplas formas, e à consciência prática individual, daquela derivada. A essas duas últimas formas de consciência, em rigor, poder-se-ia designar, respectivamente, consciência antecedente e consciência consequente; ambas, típicas ou, antes, resultantes do pensamento da representação. Nessa perspectiva, de início, o artigo apresenta as linhas gerais da syneidesis e, ato contínuo, o pensar em imagens como seu elemento próprio. 


\section{SYNEIDESIS, AQUÉM E ALÉM DA CONSCIÊNCIA PRÓPRIA DA MODERNIDADE}

A época atual caracteriza-se, de modo mais ou menos rigoroso, como faunica; refere-se, pois, ao deus Fauno, $\operatorname{Pan}(\pi \alpha v)$, que, imortal, torna-se mortal, divino, devém natural; este em oposição àquele. Essa é a época na qual, em certo sentido, ao que tudo indica, Grande Pan renasce, depois de sua suposta morte, anunciada por Epiterse e registrada por Plutarco, em De defectu oraculorum, 17, quando da emergência do Cristianismo e, com este, da representação; em rigor, da interioridade oposta à exterioridade ou do conceito do ente em oposição ao ente ele mesmo. Isso, pari passu à desdivinização da natureza, em especial da floresta e dos seres que a habitam, bem como, logo após, do próprio mundo, os quais então se veem desencantados ou pura e simplesmente racionalizados. Uma racionalização que, no limite, resulta na fragmentação do espírito; portanto, também no esfacelamento da consciência; essa guindada a princípio epocal pelos modernos, e então chamada moderna, nos limites de uma determinação formal de si mesmo e do outro. E por que Fauno renasce, senão porque a consciência deixa-se levar, mais uma vez, tal como em seus primórdios pré-modernos, mas em um horizonte pós-moderno, pelos caminhos do bosque?

A modernidade nasce com o Cristianismo, já dizia Hegel; a interioridade, com Santo Agostinho, e a representação mental, com os estoicos. Antes disso, porém, essas noçôes e as "coisas" a que elas se referem não só eram estranhas ao pensamento, mas, para este, eram mais propriamente inexistentes. Embora nasça com os estoicos, precisamente a partir da interpretação destes das Ideias de Platão e das formas de Aristóteles, a representação mental só ganha status epistêmico, com a revolução operada por Duns Scotus, nos séculos XIII e XIV, bem como status ontológico, com a revolução cartesiana do eu penso, no século XVII. Não obstante, com essa revolução, a um tempo epistêmica e ontológica, uma forma de consciência e uma forma de pensar, entre si correspondentes, foram praticamente alijadas do concerto científico e filosófico da vida humana. Tal forma de consciência não é senão a chama-

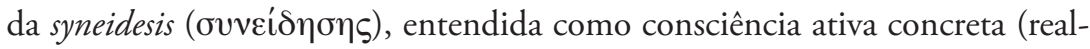
mente existente); ao passo que a referida forma de pensar consiste naquilo

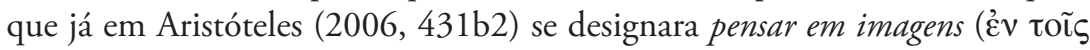

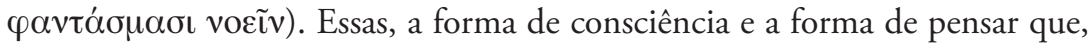
após a hecatombe da consciência moderna e do pensar abstrato, meramente representacionais, mais uma vez emergem. 
A despeito de os estudiosos, em geral, afirmarem que a syneidesis equivale à consciência moral do sujeito moderno e, com isso, a oponham à consciência teórica deste, o mais adequado, ao que parece, seria assumi-la como uma forma de conhecimento prático. Este, tal como concebido por Aristóteles, à distinção do conhecimento teorético (no qual o pensar se mantém em si) e do poiético (em que o pensar se esgota na coisa produzida), consiste em um pensar que não permanece em si e nem se esgota na coisa produzida, mas informa a ação do indivíduo e, conforme essa ação se dá, o pensar retorna a si mesmo, de modo que o indivíduo em questão se torne melhor ou pior do que era; isto é, torne-se uma pessoa virtuosa ou uma pessoa viciosa. Assim, no quadro referencial de uma vida vivida segundo a virtude ou segundo o vício, a syneidesis como que se impóe como a forma antiga de um saber de si mesmo do ser humano que poderia ser descrita como existencial.

Já em seu primeiro uso historicamente registrado, o termo syneidesis se impóe como certa tomada de consciência (prática) acerca do modo de vida que, em cada caso, segundo uma nomenclatura do século XX, mostra-se próprio ou impróprio, na medida em que se refere ao modo de ser ou de viver do indivíduo mesmo que deste se torna consciente. Ao que tudo indica, é precisamente nesse sentido que Demócrito de Abdera (DK 68 B, 297), em pleno século $\mathrm{V}$ a.C., utiliza a palavra, quando se refere, de acordo com os seus próprios termos, ao modo de vida impróprio, carcinogênico, levado por algumas pessoas durante o tempo de suas respectivas existências, no limite das quais essas pessoas náo teriam saber algum - teoricamente determinado - sobre a natureza mortal do ser humano. No dizer do filósofo,

algumas pessoas nada sabem da dissolução da natureza mortal, mas

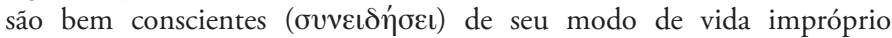

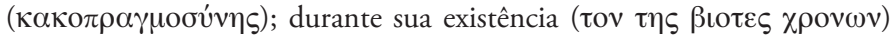
lutam em meio ao desassossego e à angústia, enquanto inventam falsos mitos sobre o tempo após o fim. (DK 68 B, 297).

Ora, a forma de consciência que emerge nesse fragmento se desenvolvera, de certa maneira, sistematicamente, no pensamento grego antigo, até pelo menos sua respectiva apropriação pelo estoicismo e pelo Cristianismo (MARIETTA JUNIOR, 1970; COOK, 2004). A dificuldade que sua investigação nos impõe está no fato de que, por tratar-se de uma forma de consciência própria do pensamento prático, em rigor, concreto e, portanto, ativo, os filósofos e pensadores antigos pouco ou nada se referiram a ela. Em vista disso, 
a mesma parece ter sucumbido ao processo de formalização - logo, de abstração - do pensamento, tal como iniciado pelos estoicos, radicalizado por Duns Scotus, completado por René Descartes, mediante a representação mental operada pela consciência teórica, e fundamentado por Immanuel Kant, com o estabelecimento das categorias e dos assim chamados juízos sintéticos a priori. Destes, em seu caráter sistemático, concebido a título de conhecimento teórico ou transcendental, o conhecimento prático é uma simples ampliação ou, antes disso, um desdobramento, no sentido da constituição de uma realidade efetiva. Esta, para falar com Hegel, a realidade própria do espírito ou da razáo que se efetua no mundo e como mundo; nesse caso, como mundo do espírito.

Pois bem, é precisamente esse mundo do espírito ou da razão universal determinada em si e para si mesma como prática, o qual, derivado ou resultante da razão pura teórica dos modernos, mostra-se como a mais completa inversão da syneidesis do mundo da natureza, tal como concebida pelos antigos, enquanto plataforma constitutiva das ações humanas. Em tal inversão, tanto a syneidesis, quanto seu correlato, o pensar em imagens - do qual se falará mais adiante -, foram como que destituídos de seu lugar de direito e subordinados à consciência teórica e ao pensamento da representação; o que, em termos míticos ou, antes, culturais, pode ser expresso como equivalente à morte do deus Fauno (Pan), precisamente quando da emergência do Cristianismo. Fauno, ou Pan, é o todo, a unidade - ou antes, o ser-um - do mundo divino e do mundo humano, do macrocosmo e do microcosmo; unidade ou, antes, ser-um, que se desfaz com a instauração do Deus cristão e a separaçáo operada por este entre Ele mesmo, enquanto criador, e sua criação, o mundo natural (e as criaturas que o habitam), em que os humanos, para fazer jus à nova divindade, entâo reconhecida como transcendente às criaturas, cindem o ser mesmo e sua representação. Caso em que o ser mesmo deixa de ser o ponto de partida da vida e do conhecimento humanos, cedendo lugar e se subordinando à representaçáo mental, em suma, à consciência teórica, típica dos modernos e contemporâneos.

O nascimento da consciência teórica tipicamente moderna implicou a dissolução do cosmos natural - bem como da comunidade ética própria - do pensamento antigo e sua transformação em mero fenômeno daquela ou para aquela consciência. Desse modo, o próprio cosmos tornou-se representação e, portanto, objeto do sujeito cognoscente, então elevado a sujeito transcendental, logo, a sujeito especulativo, absoluto, existente fora do mundo e determinante do ser ou do existir deste, assumido como realidade efetiva daquele. 
Não obstante, esse estado de coisas não poderia persistir; a representação desmoronou sobre si própria, não suportara o peso da contradição interna de si consigo mesma numa dialética muito mais destrutiva que construtiva, ou em um processo de construção ou de suprassunção que tão só apõe categorias ou determinaçóes formais ao ser mesmo, em grande parte estranhas a ele e, por isso, mostram-se incapazes de dar conta do real, sendo, portanto, insuficientes para apreendê-lo, assumi-lo ou vivê-lo segundo sua essência. Esta, diametralmente oposta àquelas categorias ou determinaçóes formais, porquanto radica no ter de ser, isto é, no existir, do real e não no seu ser representado, ou seja, no seu caráter de objeto para um sujeito.

A ciência e a filosofia contemporâneas digladiam-se pelos despojos da consciência moderna. Ao que parece, ainda náo se deram conta ou se recusam a reconhecer que já se iniciara uma nova época histórica, a qual se poderia denominar pós-moderna. Nessa nova época, não há mais lugar para cisôes ou distinçôes formais como as de ser e representação, imanência e transcendência, empírico e transcendental, finito e infinito, prático e teórico etc.; mas, antes disso, exige-se retornar à essência mesma - em sua concretude existencial - e, em seu existir, no mundo e enquanto mundo, por conseguinte, enquanto anterior àquelas cisóes, assumir seu próprio existir como seu ser o mais próprio e, assim, compreender o lugar de cada existente em sua lida com o que lhe couber de seu ser ou de sua existência. Diante disso, quando cientistas e filósofos deste século tratam da consciência, é muito difícil não notar certo mal-estar e certo labirinto terminológico, situação que pode ser caracterizada como a da fragmentação do espírito (moderno) e da consciência na qual ele se manifesta.

Limitando-nos à filosofia ou teoria da consciência, é preciso frisar que, embora criativos e até certo ponto funcionais, termos como "consciência pré-reflexiva", "consciência fenomenal não-cognitiva", "consciência afetiva”, "feeling", "senciencia animal" ou "consciência não-conceitual", entre outros, não podem ir muito longe na descrição ou na explicação daquilo que propõem, se, antes, não assumirem um ponto de partida distinto daquele da representação mental. Esta assume como pressuposto essencial, abstrato, a existência de estados mentais enquanto estados representacionais, isto é, passíveis de representação pela consciência individual (monológica), na medida em que esta é consciente dos mesmos e, portanto, os assume como objetos intencionais, os quais, embora não existam realmente, têm nela e para ela ser objetivo ou realidade objetiva; o que, levado às últimas consequências, 
implica a afirmação de que, pelo fato de certo conteúdo mental ser consciente, a consciência do mesmo é conceitual, ou de que certos animais, justamente por serem conscientes de seus estados mentais, teriam conceitos. Abstraindose do inusitado de tais assertivas, o problema que elas impóem é que, com base nos mesmos pressupostos, pode-se também afirmar que há consciência não-conceitual (cujos conteúdos mentais não seriam conscientes), consciência fenomenal não-cognitiva e assim por diante.

Em todos os casos acima aludidos, ao que parece, o pressuposto de base é a chamada consciência antecedente. Esta é assim designada pelo fato de partir do elemento teórico, conceitual, tomado como a priori, e dele derivar, por exemplo, a consciência consequente, assumida como a posteriori. Mas é possível que também ocorra o inverso, isto é, que a consciência consequente ou, mais propriamente, retrospectiva, tenha primazia em relação à consciência antecedente e que, por conseguinte, não se subordine a esta, e isso na medida mesma em que não a pressupóe para que exista realmente e não apenas formalmente enquanto consciência, nesse caso, ativa concreta. Logo, o termo "consequente" não tem nenhuma relação com o termo "antecedente" e, em vista disso, não pressupóe determinaçôes como as de a priori e a posteriori, as quais dizem respeito apenas à consciência individual teórica e à sua ampliação à consciência individual prática. Nesse sentido, "consequente" deve ser tomado como sinônimo de "responsável" - que responde por - e dessa maneira, a um tempo, como teórica e prática ou, mais propriamente, ativa concreta (realmente existente).

Há pelo menos uma forma de consciência - na história do pensamento humano - que confirma o referido caso, isto é, a syneidesis. Porque não parte de estados mentais (portanto individuais) formalmente conscientes, mas de açóes e fatos concretos intersubjetivamente compartilhados e, só assim, interiorizados - inclusive como estados mentais - ela não se configura de saída (ou em princípio) como conceitual; portanto, não se constitui como eu ou como uma representação de si do si mesmo enquanto sujeito de representaçóes. Ao contrário, ela está mais próxima daquilo que Freud designou Além-eu e, por isso, como consciência ativa concreta (realmente existente), não se perfaz senão sob a forma de um conhecimento prático autônomo (em relação ao teórico, tomado separadamente) e, enfim, como consciência prática. Ainda que tal aproximação pareça ter permanecido inconsciente para o próprio Freud - sobretudo no que diz respeito, conforme Nauss (1962, p. 273ss), ao seu alinhamento com a Bíblia cristã -, o fato é que, se se abstrai da noção de 
Eu (enquanto unidade sintética da apercepção e portanto da síntese que no Eu e pelo Eu se processa), precisamente como uma instância psíquica emersa na modernidade e, por isso, especificamente moderna, torna-se claro em que medida, para o psicanalista, o Além-eu unifica em si tanto as influências do Isso quanto as do mundo exterior (FREUD, [1924] 2016, p. 274), subsistindo, pois, como uma instância única tanto no indivíduo quanto na comunidade da qual ele é parte. Essa instância única, em certo sentido, constitui-se entre os antigos como a própria syneidesis, caso em que aquela unificação se impóe como sua atividade precípua.

Em vista disso, entre os antigos, é precisamente a partir da syneidesis que a atividade do sábio se mostra exemplar e, portanto, um exemplo a ser seguido. Entretanto, com a distinçáo medieval entre uma consciência teórica, de um lado, cognitiva e assim intelectual, designada por Descartes logo após pela expressão eu penso, e, de outro lado, uma consciência ética ou moral, afetiva ou emocional, ficando a syneidesis restrita a essa última, pode-se sustentar que uma outra cisão ocorre, da qual, com base no modelo kantiano das faculdades de desejar inferior ou empírica e superior ou transcendental, Freud, à luz de Nietzsche, mostrará a emergência do Isso e do Além-eu. Essa a razão pela qual, se lida a partir da syneidesis, a unificação das influências do Isso e as do mundo exterior pelo Além-eu nele mesmo tornar-se, de certo modo, conforme os termos do próprio Freud ([1924] 2016, p. 274), "um modelo ideal daquilo a que visa todo o anseio do Eu."

Tal como aqui considerada, a syneidesis consiste numa determinação real, no quadro teórico-prático do que o autor designa Teoria do abrangente, da consciência ativa concreta, intersubjetivamente compartilhada, a qual se mostra a um tempo prática e social. A teoria do abrangente (ainda em elaboraçáo) se desdobra numa teoria do ser, numa teoria da vida e numa teoria da inteligência (a um tempo, divina, natural e artificial), em cujo início se impóe a syneidesis, no sentido acima indicado, como fundamento e ponto de partida de uma teoria da consciência (e da autoconsciência) intersubjetivamente compartilhada. Desse modo, abstraindo-se aqui de todo um desenvolvimento sistemático, pode-se asseverar que a syneidesis se constitui como uma determinação do abrangente, no nível da consciência, que é, por seu turno, e tal como a inteligência, igualmente divina, natural e artificial. Essas duas últimas são como que as respectivas contrapartes que conformam aquela (despida de aspectos religiosos, históricos ou institucionais), que se impóe como a syneidesis propriamente dita e, enfim, como o abrangente, no nível da consciência. 
Nesse caso, tal consciência não pode ser um eu, nos limites da cisão do Eu mesmo entre um eu teórico e um eu prático, mas, antes, constituir-se como aquém e além do próprio Eu.

A um tempo aquém e além do Eu, a syneidesis conforma-se a partir do que designamos pensar em imagens, que é cognitivo e não-conceitual ou não representacional. Este não é um pensar abstrato, mas, antes, um pensar concreto; portanto, também não é o pensar de uma consciência teórica, isto é, formal (abstrata) ou reflexivamente cônscia de si mesma, contudo, configura-se como o pensar de uma consciência prática ou concretamente cônscia de si mesma. Essa não é abstratamente cognitiva, intelectiva ou intelectual (no sentido de uma awareness ou de uma consciousness) e sim afetiva e sensitiva ou emocional, porque prática (uma conscience) ou, a um só tempo, ativa e concreta. Isso não significa que tal consciência não tenha nenhum elemento teórico, mas apenas que a teoria é certo grau de compreensão de si mesma, a qual ela atinge enquanto consciência ativa concreta. Assim, transposta para o silogismo, por exemplo, ela implica que a conclusão deste não seja uma outra proposição formal e sim uma ação; caso em que, à diferença dos modernos e, tal como os antigos, o afetivo e o sensitivo ou o emocional náo estão separados do cognitivo, do intelectivo ou do intelectual, separação que o pensar em imagens vem abolir, bem como a teoria do abrangente. A syneidesis não é uma consciência abstrata, portanto, nem reflexiva nem pré-reflexiva, para nos limitarmos a essas duas determinaçôes, mas é, antes de tudo, uma consciência concreta e, por isso, compreensiva.

Porque compreensiva, a syneidesis é anterior à distinção de consciência de acesso e de consciência fenomenal, bem como à distinção de consciência fenomenal não-conceitual (não-cognitiva ou pré-reflexiva) e de consciência fenomenal conceitual (cognitiva ou reflexiva). Como consciência ativa concreta, ela é, antes de tudo, uma consciência de natureza prático-social ou ético-política, e só é consequente, na medida em que resulta de uma implicação explícita, sem a qual ela se limita ao elemento pré-compreensivo, porque préconsciente e mesmo inconsciente de sua condição. Isso acarreta, finalmente, seu caráter a um tempo teórico e prático, o qual se mostra em seu elemento próprio apenas no que designamos pensar em imagens. 


\section{III À GUISA DE CONCLUSÃO: PENSAR EM IMAGENS, ELEMENTO PRÓPRIO DA SYNEIDESIS}

Embora considerado em linhas gerais por Aristóteles, nos capítulos sete e oito do livro III do De anima, o pensar em imagens jamais fora tematizado em detalhe pelo estagirita ou mesmo pelos scholars, inclusive os antigos. Exemplos disso são os comentadores de Aristóteles da Escola de Amônio9 e os filósofos que disputavam o legado de Aristóteles, nos séculos XIII e XIV, em grande parte já prenunciando o pensamento da abstração, em especial, Tomás de Aquino e Duns Scotus, este, sobretudo, em sua discussão com Henrique de Gand (THOMAS AQUINAS, $1951 \$ 777$, \$792; DUNS SCOT, 1993, \$340, \$391-392) Náo obstante, antes dos séculos XIII e XIV, Plotino e Proclo, e depois Giordano Bruno ${ }^{10}$, aplicam-se à questão do pensar em imagens, sempre a partir de Aristóteles, e a ela dedicam um lugar importante. De nossa parte, tematizaremos pelo momento apenas dois aspectos desse pensar, essenciais para a questão ora tratada. ${ }^{11}$

Um primeiro aspecto importante do pensar em imagens, tal como tratado por Aristóteles, é o fato de que "o capaz de pensar pensa as formas, portanto, em imagens, e como nestas está definido para ele o que deve ser perseguido e o que deve ser evitado, então, mesmo à parte da sensação, ele se move quando está diante das imagens." 12 É possível distinguir quatro elementos essenciais do pensar em imagens já nessa primeira afirmação, a saber: (1) as formas são pensadas em imagens; (2) as formas são conteúdo das imagens, que, portanto, as configuram como tais; (3) as imagens definem o que deve ser perseguido e o que deve ser evitado; (4) as imagens implicam movimento, ação. Temos aqui a estrutura geral do pensar em imagens, a qual se impóe, necessariamente, a um tempo, tanto como a estrutura do conhecimento teorético quanto do prático e do poiético; na sequência de seu texto, Aristóteles exemplifica sua afirmaçáo, de modo a privilegiar, sobretudo, o conhecimento prático - entendido como o âmbito do que é provido de ação -, mas também mostrando sua pertinência para o que é desprovido de ação - o verdadeiro e o

\footnotetext{
${ }^{9}$ Considere-se o parágrafo dedicado por Simplício a De anima, III, 7, 431b2-5. Ver Simplicius, (2014, p. 273).

${ }^{10}$ Ver Plotin (1954, 4 [46], 10); Proclus (1970), 51ss/41ss); Nolano (2010), p. 52/207.

${ }^{11}$ Para uma consideração aprofundada do pensar em imagens em Aristóteles, ver Da Silva (2019 no prelo).

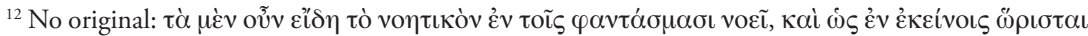

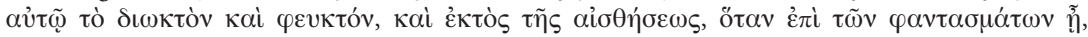

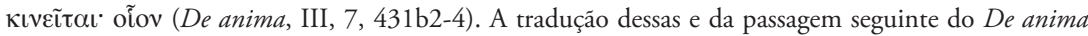
segue a versão brasileira de Maria Cecília Gomes dos Reis, ligeiramente modificada.
} 
falso - incluindo as coisas que se dizem por abstração. Nesse caso, porém, ele deixa em aberto a possibilidade de o intelecto pensar alguns objetos separados, abstraídos das imagens (De anima, III, 7, 431b12-19).

Outro aspecto da concepção aristotélica do pensar em imagens, aqui essencial e que confirma a assertiva acima citada, é a clara exemplificação dessa forma de pensar e sua distinção em relação ao pensar por abstração:

Uma vez que tampouco há, ao que parece, qualquer coisa separada e à parte de grandezas sentíveis, os inteligíveis estáo nos sensíveis, tanto os ditos por abstração como também todas as disposiçóes e afecçôes dos que são sentíveis. Por isso, se nada é sentido, nada se aprende nem se compreende, e, quando se contempla, há necessidade de se contemplar ao mesmo tempo alguma imagem, pois as imagens são como que sentidas, embora desprovidas de matéria. E a imaginação é diferente da asserção e da negação: pois o verdadeiro e o falso são uma combinaçấo de pensamentos. Em que os primeiros pensamentos seriam diferentes de imagens? Certamente nem estes e nem os outros são imagens, embora também não existam sem imagens. (De anima, III, 8, 432a3-14) ${ }^{13}$

Dessa passagem, podem-se elencar diversos elementos estruturantes do pensar em imagens: (1) não há nada separado, à parte das grandezas sentíveis; (2) todos os inteligíveis estâo nos sensíveis; (3) a sensação é a condição fundamental do aprendizado, da compreensão e da contemplação; (4) a contemplação necessita da imagem para realizar-se como tal; (5) as imagens não são sensíveis, porque desprovidas de matéria, mas são como que sentidas; (6) os primeiros pensamentos (que são concretos ou, ainda, intuiçóes) não se distinguem das imagens; (7) os pensamentos não são imagens, mas não existem sem imagens. Considerando em conjunto a citaçáo logo acima e a anterior, é possível formar um quadro referencial mínimo, mas consistente, da concepçáo aristotélica do pensar em imagens e, portanto, do próprio pensar em imagens e da syneidesis, aqui assumida e mantida como a forma de consciência própria desse pensar. Na medida em que tal pensar se mostra

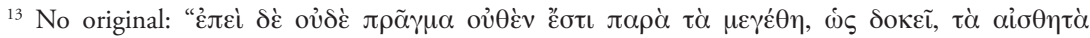

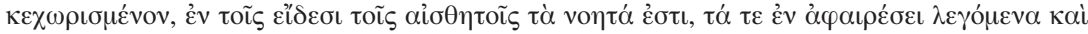

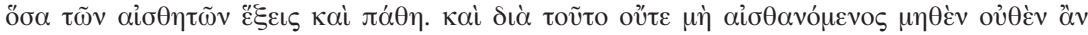

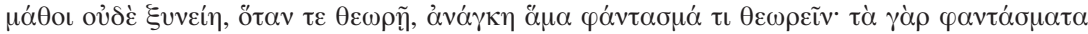

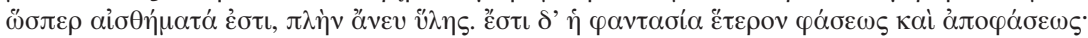

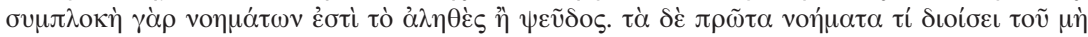

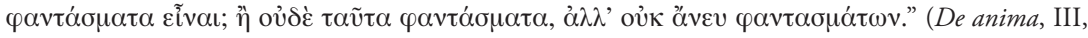
8, 432a3-14). 
eminentemente ativo e concreto, náo separando, por conseguinte, a forma (eidos) e a imagem (phantasma), a interação de ambas implica necessariamente um saber em comum com os outros (syneidos). Dois exemplos importantes dessa interação nos são dados por ninguém menos que Freud, um positivo e outro negativo.

Para Freud ([1923] 2015, p. 290), “o pensar em imagens está mais próximo dos processos inconscientes que o pensar em palavras.” Isso significa que o pensar em imagens difere do pensar em palavras, conceitual, na medida em que seu campo de ação pervade o campo da consciência teórica, esta, designada o sistema consciente, então privilegiado por Freud em relação aos sistemas préconsciente e inconsciente. Uma aplicação prática desse ponto de vista, fundado na primazia do eu individual ou do consciente para a vida considerada normal, consiste na afirmação do próprio Freud ([1921] 2015, p. 72) segundo a qual a massa é impulsiva e dirigida quase exclusivamente pelo inconsciente, sendo destituída de crítica, razão pela qual ela pensa em imagens. Isso se justifica por uma assertiva de Varendonck (1921, p. 68) de que "o pensamento verbal - em palavras ou em conceitos abstratos - é muito mais breve do que pensar em imagens." Em tal situação, este, à diferença daquele, não se dobra à direção do eu e mais facilmente se póe fora de controle.

Concorde-se ou não com Freud, seus exemplos se mostram essenciais para uma compreensão adequada do pensar em imagens num quadro em que este ainda se apresenta subordinado ao pensar por conceitos. O psicanalista, embora defensor da primeira forma de pensar, está a anos-luz de sua concepção autêntica, o que lhe impede o acesso a um entendimento mais consistente do próprio Além-eu, porquanto este, como se aludiu mais acima, se aproxima de modo ineludível da syneidesis, mesmo em sua acepção bíblica. Contudo, talvez por ainda se apegar demais ao Eu ou à consciência teórica, o fundador da psicanálise não se deu conta da revolução que uma afirmação mais resoluta do pré-consciente do pensar em imagens poderia antecipar. Hoje, vivemos essa condição, a qual nos pode fornecer as chaves para uma compreensão adequada não só da consciência, mas também do próprio fundamento desta, o abrangente.

SILVA, M. M. Syneidesis, beyond the fragmentation of the spirit: an introduction to the theory of concrete consciousness and of thinking in images. Trans/Form/Ação, Marília, v. 41, p. 13-30, 2018. Edição Especial. 
ABstract: This article discusses the emergence of syneidesis (as active concrete consciousness) and thinking in images, as opposed to contemporary discussions about consciousness and thought as abstract representations. The working hypothesis assumed is that syneidesis - as sociocultural or ethical-political consciousness, which medieval thinkers called conscientia consequens (retrospective consciousness) - is historically and ontologically prior to the individual theoretical consciousness in its manifold forms and to the individual practical consciousness derived from it. The latter two are forms of what may be called conscientia antecedens (antecedent consciousness), and are typical of the thought of representation. From this perspective, the article first presents the general lines of syneidesis and then discusses thinking in images in its own right.

KeYwORDs: Syneidesis. Conscience. Thinking in images. Representation.

\section{REFERÊNCIAS}

ALBERTUNI, C. A. O termo sindérese e sua introdução no pensamento medieval. Àgora Filosófica, ano 10, n. 1, p. 15-22, jan./jun. 2010.

ARISTÓTELES. De anima. Apresentação, tradução e notas de Maria Cecília Gomes dos Reis, Rio de Janeiro: Editora 34, 2006.

ARISTOTLE. De anima. Translation, introduction and notes by R. D. Hicks. Cambridge: Cambridge University Press, 1907.

COOK, E. Conscience in the New Testament. Journal of the Adventist Theological Society, v, 15, n.1, p. 142-158, Spring 2004.

DA SILVA, M. M. O problema do início e a questão do abrangente: linhas fundamentais de uma metafísica pós-moderna. In: . (org.). Ser e pensar, inícios. São Paulo: Todas as Musas, 2016. p. 221-254.

- A concepção aristotélica do pensar em imagens: nota sobre seu influxo na lógica e na metafísica. Humus, 2019. No prelo.

DEMÓCRITO DE ABDERA. Fragmentos. DK 68 B, 297. In: DIELS-KRANZ. Die Fragmente der Vorsokratiker. Berlin: Weidmannche Buchhandlung, 1922.

DUNS SCOT. L'Image, Paris: Vrin, 1993.

DUPONT, J. Syneidèsis: aux origins de la notion chrétienne de conscience morale. Studia Hellenistica, v. 5, p. 119-153, 1918.

FREUD, S. Gesammelte Werke (Kindle, ebuch folgt dem Originaltext). E-artnow, 2015: Das Ich und das Es (1923).

. Gesammelte Werke (Kindle, ebuch folgt dem Originaltext). E-artnow, 2015:

Massenpsychologie und Ich-Analyse (1921).

. Neurose e psicose. In: FREUD, S. Neurose, psicose, perversão. Tradução de Maria

Rita Salzano Moraes. Belo Horizonte: Autêntica, 2016. p. 274. (Original 1924). 
MARIETTA JUNIOR, D. E. Conscience in Greek Stoicism. Numen, v. 17, n. 3, p. 176$187,1970$.

MERLAN, P. Metaphysica generalis in Aristotle. In: From platonism to neoplatonism. 3th ed. revised. Hague: Martinus Nijhof, 1975. p. 169-174.

NAUSS, A. Freud's superego and the Biblical Syneidesis. Concordia Theological Monthly, v. XXXIII, n. 5, p. 273-282, May 1962.

NOLANO, G. B. Il primo libro della Clavis Magna: Ovvero il trattato sull”intelligenza artificiale. Traduzione, introduzione e note di Claudio D’Antonio. Roma: Di Renzo, 2010.

OJAKANGAS, M. Arendt, Socrates, and the ethics of conscience. In: (ed.). Hannah Arendt: practice, thought and judgement. Helsinki: Helsinki Collegium for Advanced Studies, 2010. p. 67-85.

PLOTIN. Ennéades I: Texte établi et traduit par Émile Bréhier. 2. ed. Paris: Les Belles Lettres, 1954.

PROCLUS, Commentary on the first book of Euclid's elements. Translated with introduction and notes by G. R. Morrow. Princeton: Princeton University Press, 1970.

SCHINKEL, A. Conscience and conscientious objections. Amsterdam: Amsterdam University Press, 2006.

SCHMITT, A. Die Moderne und Platon. 2. Auflage. Weimar: J. B. Metzler, 2008.

SIMPLICIUS. On Aristotle On the Soul 3.6-13. Translated by Carlos Steel in Collaboration with Arnis Ritups. London; New York: Bloomsbury, 2014.

THOMAS AQUINAS. Commentary on Aristotle's De anima. London: Routledge and Kegan Paul, 1951.

VARENDONCK, J. The psychology of day-dreams. London: George Allen \& Unwin; New York: The Macmillan Company, 1921.

VIRASORO, R. La consciência moral y los valores. Dianoia, v. 9, n. 9, p. 258-281, 1963.

WALDMANN, M. Synteresis oder syneidesis. Theol. Quartalschrift, Heft III, p. 332-371, 1938.

WOODRING, B. Paul and Stoicism. December 3rd, 2012. A paper discussing Stoicism and its possible influence on Paul. Disponível em: www.scribd.com, enviado por Ben Woodring em Aug 30, 2013. Direitos autorais: Attribution Non-Commercial (BYNC). Acesso em: 14 nov. 2018).

Recebido: $15 / 11 / 2018$

Aceito: $15 / 11 / 2018$ 
SILVA, M. M. 